\title{
Arte-Ciência-Tecnologia: Transdisciplinaridade como Argumento Curatorial em Três Exposições de Arte Contemporânea
}

Nara Cristina Santos possui Pós-doutorado em Artes Visuais/UFRJ. Doutora em Artes Visuais/UFRGS com estágio na Paris VIII/França. Professora do DART/ UFSM desde 1993, atua na Graduação e Pós-Graduação das Artes Visuais/PPGART. Pesquisadora em História, Teoria, Crítica e Curadoria, com projetos transdisciplinares em Arte-Ciência-Tecnologia. Coordena o LABART www.ufsm. br/labart e lidera o grupo de pesquisa Arte e Tecnologia/CNPq. Organizadora e curadora do Festival Arte Ciência e Tecnologia/FACTORS. Tem convênios, projetos e publicações no Brasil e exterior. Consultora da CAPES para área de Artes. Membro do Comitê Brasileiro de História da Arte (CBHA) e da Associação Nacional de Pesquisadores em Artes Plásticas (ANPAP), que presidiu no biênio 2015-2016.

<gnaracris.sma@gmail.com> ORCID: 0000-0003-4968-2738
Resumo Este artigo trata de um estudo sobre três exposições de Arte-Ciência-Tecnologia organizadas por pesquisadores, entre curadores e artistas, de diferentes Instituições de Ensino Superior no Brasil e na Argentina: Mata - 200 milhões de anos (2011), FACTORS 4.0 (2017), Transdisciplinaridade Arte, Ciência e Neurociência (2020). A curadoria compartilhada busca, tanto na estratégia expositiva quanto no desafio teórico, discutir a concepção de transdisciplinaridade como argumento curatorial. Esta concepção é aliada a diferentes conceitos em cada uma das mostras e gera questões emergentes, provocadoras de novas práticas expositivas e outros discursos para contribuir com o campo da Arte Contemporânea e sua história.

Palavras chave Exposições, Arte Ciência Tecnologia, Transdisciplinaridade, Arte Contemporânea, História da Arte. 


\title{
Art-Science-Technology: Transdisciplinarity as a Curatorial Argument in Three Contemporary Art Exhibitions
}

\begin{abstract}
This article is about a study on three Art-Science-Technology exhibitions organized by researchers, between curators, scientists and artists, from different Higher Education Institutions in Brazil and Argentina: Mata - 200 million years (2011), FACTORS 4.0 (2017), Transdisciplinarity Art, Science and Neuroscience (2020). Shared curation seeks, both in the expository strategy and in the theoretical challenge, to discuss the concept of transdisciplinarity as a curatorial argument. This conception is combined with different concepts in each of the exhibitions and generates emerging questions, provoking new exhibition practices and other discourses to contribute to the field of Contemporary Art and its history.
\end{abstract}

Keywords Exhibitions, Art Science Technology, Transdisciplinarity, Contemporary Art, Art History.

Arte-Ciencia-Tecnología: transdisciplinariedad como argumento curatorial en trés exposiciones de Arte Contemporáneo

Resumen Este artículo trata de un estudio sobre tres exposiciones de Arte-Ciencia-Tecnología organizadas por investigadores, entre curadores, cientistas y artistas, de diferentes Instituciones de Educación Superior en Brasil y Argentina: Mata - 200 millones de años (2011), FACTORS 4.0 (2017), Transdisciplinariedad Arte, Ciencia y Neurociencia (2020). La curaduría compartida busca, tanto en la estrategia expositiva como en el desafío teórico, discutir la concepción de transdisciplinariedad como argumento curatorial. Esta concepción se conjuga con diferentes conceptos en cada uma de las muestra y genera preguntas emergentes, provocando nuevas prácticas expositivas y otros discursos para aportar al campo del Arte Contemporáneo y su historia.

Palabras clave Exposiciones, Arte Ciencia Tecnología, Transdisciplinariedad, Arte Contemporáneo, Historia del Arte. 


\section{Transdisciplinaridade como argumento curatorial}

A produção em Arte-Ciência-Tecnologia pode ser entendida como uma tendência, entre outras, na Arte Contemporânea. Para pensar o contemporâneo, partimos de Groys ${ }^{1}$, para quem ser "con-temporâneo" é o camarada do tempo, alguém que "colabora com seu tempo". Entre os artistas contemporâneos que colaboram com o seu tempo, estão aqueles que lançam ideias, propõe questões emergentes e produzem nas confluências e interseções da Arte-Ciência-Tecnologia ${ }^{2}$. Eles têm uma atuação comprometida com as questões de seu tempo, sejam elas quais forem, inclusive com o modo de produzir e exibir obras cuja temporalidade se estabelece no acontecimento da presença, participativa, interativa e imersiva, para um público ativo. Essa atuação favorece tanto a discussão e entendimento conceitual que as obras suscitam para a Arte Contemporânea, nas distintas estratégias curatoriais formalizadas e ou experimentais, quanto naquilo que elas podem contribuir para uma História da Arte pensada a partir de exposições.

Enquanto os artistas investigam outras linguagens e tendências em Arte-Ciência-Tecnologia, os historiadores, teóricos e críticos também pesquisam estratégias curatoriais, práticas expositivas, dispositivos expográficos e entrecruzamentos conceituais com a Arte Contemporânea. Nesse sentido, uma concepção surge, a partir do trabalho que desenvolvo como curadora ao longo do tempo, e instiga a pesquisa entre as distintas áreas: a transdisciplinaridade.

Este artigo trata de três exposições que têm como estratégia curatorial uma concepção de transdisciplinaridade e um conceito específico a cada mostra, que perpassa e problematiza questões de Arte-Ciência-Tecnologia para tratar, entre outras, das produções interativas em arte digital, arte computacional, arte e robótica, arte e ciência, arte e natureza. Cada exposição tem como argumento curatorial transdisciplinar seu respectivo conceito: "Mata 200 Milhões de Anos" (2011), o de nanoarte; "FACTORS 4.0" (2017), o de bioarte; e, "Transdisciplinaridade Arte Ciência e Neurociência", o de neurociência (2020).

A curadoria aponta muitas vezes questões complexas $^{3}$ para a Arte Contemporânea, não necessariamente difíceis de resolver, mas sempre provocadoras de novas estratégias em Arte-Ciência-Tecnologia. Entre elas, entender não apenas a atuação do curador diante de uma abordagem transdisciplinar, mas compreender inicialmente que estamos todos diante da diversidade de linguagens e da pluralidade de tendências próprias da contemporaneidade. $O$ que inclui a produção associada diretamente a dada especificidade tecnológica, seja ela mais ou menos vinculada à ciência. Por exemplo, entre as linguagens e tendências, desde videoarte, webarte, arte telemática, bioarte, nanoarte, arte robótica, mobile arte, arte sonora, performances e instalações multimídia, virtuais, interativas, imersivas, projetos em realidade virtual, aumentada, mista, até pesquisas com seres vivos, 
semivivos ou não vivos. $\mathrm{Na}$ atuação curatorial hoje, pode-se compreender esta diversidade como um campo no qual emergem poéticas artísticas híbridas, em torno da transdisciplinaridade.

No $1^{\circ}$ Congresso Mundial sobre Transdisciplinaridade, realizado no Convento da Arrábida, Setúbal/Portugal, em 1994, se apresenta e se discute a Carta da Transdisciplinaridade ${ }^{4}$, de Basarab Nicolescu, Edgar Morin, e Lima de Freitas. Desta carta, três artigos podem ser destacados:

Artigo 3: A transdisciplinaridade é complementar à aproximação disciplinar: faz emergir da confrontação das disciplinas dados novos que as articulam entre si; oferece-nos uma nova visão da natureza e da realidade. A transdisciplinaridade não procura o domínio sobre as várias outras disciplinas, mas a abertura de todas elas àquilo que as atravessa e as ultrapassa.

As diferentes disciplinas do campo científico e artístico dialogam de modo igual e aberto para pensar outra realidade. E, neste caso, para a produção de obras de arte que se constituem como projetos cuja concepção transdisciplinar é atravessada por conceitos emergentes.

Artigo 5: A visão transdisciplinar está resolutamente aberta na medida em que ela ultrapassa o domínio das ciências exatas por seu diálogo e sua reconciliação não somente com as ciências humanas mas também com a arte, a literatura, a poesia e a experiência espiritual.

Compreender a reconciliação das ciências com a arte, também significa dar-se conta que suas inter-relações podem ser pensadas a partir da arte para com as ciências, pois não deveria haver domínio de uma sobre a outra.

Artigo 6: Com relação à interdisciplinaridade e à multidisciplinaridade, a transdisciplinaridade é multidimensional. Levando em conta as concepções do tempo e da história, a transdisciplinaridade não exclui a existência de um horizonte trans-histórico.

A concepção multidimensional aponta a temporalidade como essencial para pensar um horizonte trans-histórico, mas também pode levar a compreender que o pensamento científico já é trans-histórico ${ }^{5}$. 
Entende-se a transdisciplinaridade neste artigo, no seu diálogo e reconciliação com a arte, como 'além do campo, fora do campo, outro campo', o que pressupõe disciplinas que cooperam entre si, além e através delas mesmas, para um projeto comum que gera unidade no resultado. E compreende-se o diálogo transdisciplinar não apenas como um modo de organizar o conhecimento a partir de diferentes disciplinas, para constituir um pensamento sistêmico, mas também como um modo de se deixar atravessar, na produção poética em Arte-Ciência-Tecnologia, por uma ação complexa.

Nestas três exposições a curadoria é compartilhada ${ }^{6}$, desta autora com pesquisadores da mesma área, mas também colaborativa, ou seja, com profissionais de outras áreas de conhecimento atuantes mais como colaboradores do que propriamente curadores. Essa é uma questão interessante para pensar do ponto de vista do lugar da prática e da pesquisa de cada um, o cientista e, nesse caso, não o artista, mas o curador de exposições de arte.

Explorar a transdisciplinaridade na Arte e nas Ciências levanta questões sobre os aspectos epistemológicos inerentes ao cruzamento das Ciências com as Artes. (...) Como podemos articular o procedimento experimental redutivo, mas rigoroso, com uma evolução necessária para novos paradigmas que são simultaneamente complexos e abertos? Os artistas também enfrentam paradigmas de seu tempo? Ou se envolver nas artes implica se libertar de paradigmas restritivos?"7

Esse questionamento remete a exposição Mata 200 milhões de anos (2011). Na curadoria colaborativa desta mostra, a experiência vivenciada entre pesquisadoras das Artes e das Ciências, demonstrou que era preciso não apenas reconhecer os paradigmas que nutrem as distintas áreas, mas discutir e propor inicialmente outros em consonância com a proposta transdisciplinar. Ou seja, algo além do campo para compreender as interseções da Arte-Ciência-Tecnologia na sua complexidade estética, artística, científica e tecnológica, desde as diferentes áreas de conhecimento. Talvez a ação colaborativa tenha levado a pensar outros paradigmas, ao mesmo tempo em que revelou a necessidade de libertar-se de qualquer modelo. Nesse sentido, a ideia tem sido conectar diferentes disciplinas ao trabalho curatorial, para manter contato com outras áreas ou subáreas para gerar não apenas uma exposição, mas produção de conhecimento a partir da experiência transdisciplinar.

Walter Zanini (1925-2013) afirmava que, já na década de 1960, a História da Arte passa a ser mais transdisciplinar, conjugando outras disciplinas como a sociologia e a psicologia. Mas é somente com as novas mídias na arte, quando a obra única dá lugar aos dispositivos, aos vídeos, filmes, fotos, e quando a questão do espectador também é repensada de alguém mais passivo para exercer uma interação, que começa a surgir a relação en- 
tre o historiador da arte e as linguagens eletrônicas. A história da arte pode, então, para ele, se constituir a partir das exposições, e acomodar práticas artísticas intermédias e de escopo transdisciplinar.

A transdisciplinaridade é, portanto, a concepção que perpassa todo argumento curatorial das exposições realizadas, não como uma defesa de ideia das curadoras, mas como uma definição, ela mesma, de um conjunto de atividades desenvolvidas em laboratório e grupo de pesquisa institucionais ${ }^{9}$. Estas ações fundamentam tanto a organização das exposições em Arte-Ciência-Tecnologia, quanto o discurso das curadoras para com a História da Arte.

Como se constitui o discurso das curadoras ${ }^{10}$ ? Neste caso parte-se de um discurso prévio para reafirmar a produção em Arte-Ciência-Tecnologia como uma tendência da Arte Contemporânea. O que se defende como discurso, tanto no projeto quanto na atuação, é uma estratégia curatorial compartilhada ou colaborativa, desafiadora a partir da concepção transdisciplinar ao propor um conceito problematizador para pensar cada exposição. $O$ trabalho da curadoria busca selecionar artistas e obras, discutir questões emergentes a cada argumento curatorial e contribuir para o conjunto de soluções da mostra, tanto teórico-críticas, quanto prático-expográficas. Ainda, debater a atividade do curador também como crítico, no contexto institucional dos espaços de exibição públicos, como museus, galerias e salas de exposição, não necessariamente vinculados ao mercado da arte. Para tratar do argumento curatorial transdisciplinar, seguem três exposições, das quais são apresentadas uma obra de cada.

\section{Exposição Mata 200 milhões de anos" - Obra "Tecendo o Tempo ou Sendo Tecida pelo Espaço" (2011)}

A exposição Museu Interativo Arte, Ciência, Tecnologia e Patrimônio Cultural: Mata 200 milhões de anos, no Museu de Arte de Santa Maria, configura-se como transdisciplinar envolvendo diferentes áreas através de uma curadoria colaborativa. A obra "Tecendo o Tempo ou Sendo Tecida pelo Espaço", de Anna Barros, está fundamentada no conceito de nanoar$t^{12}{ }^{12}$, como concepção transdisciplinar em Arte, Ciência e Nanotecnologia. Para a artista a obra faz parte do conjunto de instalações realizadas a partir de fragmentos de uma árvore petrificada colhida na cidade da Mata-RS ${ }^{13}$, um Ypê e sua semente.

\footnotetext{
Nesta obra, as amostras são da árvore petrificada, varridas no microscópio de força atômica que, tornam-se atuantes, dentro do universo poético, em três animações digitais em 3D; elas conservam a percepção tátil da topografia gerada pelos microscópios. Enfatizando a percepção tátil e háptica, reinantes no mundo da nano, duas das animações são projetadas
} 
sobre um tapete texturizado, detonadas pela movimentação das pessoas. Elas guardam a característica de tecitura de animações renderizadas em wire frame. Outra animação é vista sobre a parede fronteira, anexa ao tapete, gerando um ambiente imersivo e interativo. ${ }^{14}$

Fig 1. Tecendo o Tempo ou Sendo Tecida pelo Espaço (2011) | Instalação interativa/nanoarte/animação digital 3D. Fotografia: Acervo LABART/UFSM.
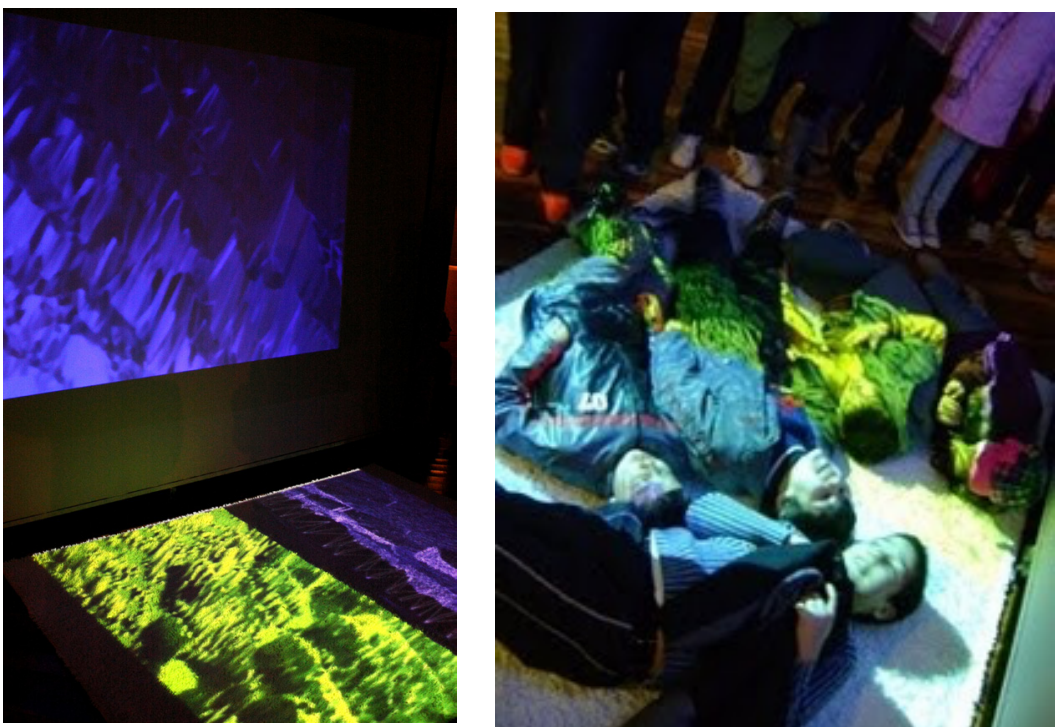

O conceito transdisciplinar de nanoarte vincula-se a Nanotecnologia na área da Engenharia Molecular, ou da ciência dos materiais, para se aproximar de nanopartículas gerando imagens de interesse estético, por exemplo. Na produção em Arte-Ciência-Tecnologia proporciona pesquisas de imagens em escala nano, obtidas através de microscópio (Eletrônico de Varredura e de Força Atômica). Nesta obra, são exploradas imagens de madeira petrificada de um sítio paleobotânico. Na Arte Contemporânea, a nanoarte pode se constituir como uma tendência de pesquisa transdisciplinar, para discutir não apenas as relações de escala, mas também de espaço e tempo em torno da matéria.

\section{Exposição FACTORS 4.015 \\ - Obra "Bot_anic" (2012)}

No Festival Arte Ciência e Tecnologia, o argumento curatorial transdisciplinar está fundado em conceitos diferentes a cada ano, como por exemplo bioarte na quarta edição. Em 2017 o evento ocorre no espaço expositivo da Sala Cláudio Carriconde, no Centro de Artes e Letras da Universidade Federal de Santa Maria. O conceito de bioarte pode apontar não apenas uma pesquisa da área da Arte entrelaçada com a área da Biologia, mas, também, da Biotecnologia e da Bioengenharia. ${ }^{16}$ 
Na relação mais direta entre arte, biologia, tecnologia e a natureza o artista Guto Nóbrega, com apoio do Grupo NANO da Universidade Federal do Rio de Janeiro, apresenta um trabalho com plantas e microambientes, em uma concepção denominada por ele como hiperorgânica. Na obra Bot-anic (2012), ele cria um ser híbrido entre o orgânico e o artificial, composto por uma planta e por um sistema robótico e convida o público a presenciar a planta reagindo ao ambiente, em estado de repouso e de interação. O sistema robótico permite que a planta reaja tanto ao ambiente quanto ao visitante na exposição, e se desloque para onde há luz, ingrediente fundamental para sua sobrevivência. $O$ trabalho permite refletir sobre uma possível autonomia das plantas e seus comportamentos emergentes, em uma experiência que pode afetar a consciência do interator sobre a relação entre plantas e máquinas e ampliar a sua compreensão do meio ambiente.
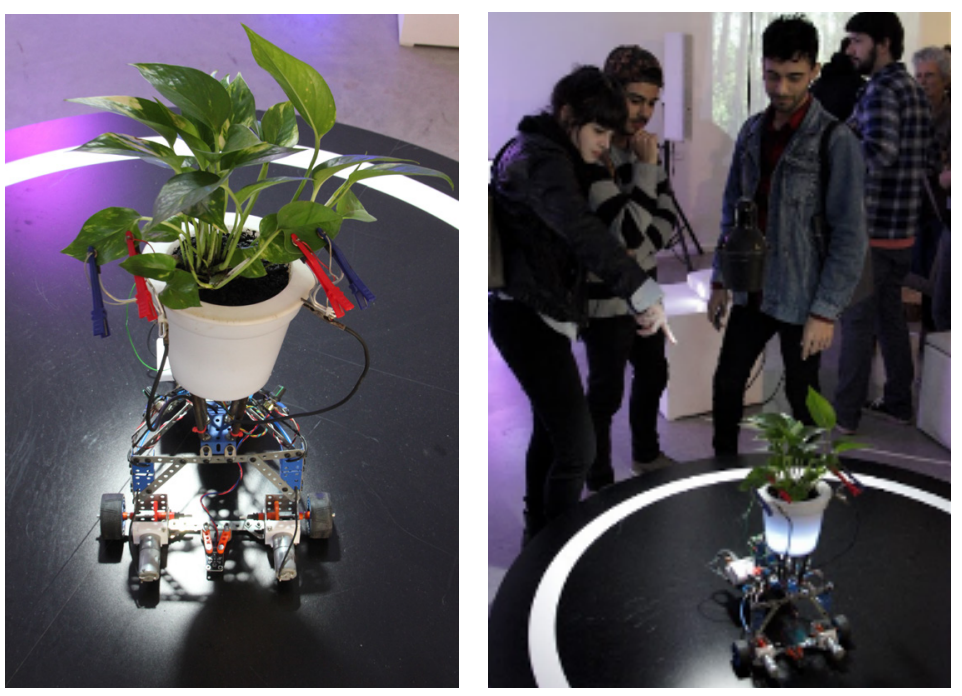

Fig 2. Bot_anic (2012), Guto Nóbrega e NANO/UFRJ. | Bioarte/Robótica/Instalação interativa.

Fotografia: Acervo LABART/UFSM.

O conceito de bioarte acolhe diferentes práticas artísticas produzidas através de seres vivos e recursos naturais em contato com meios e tecnologias artificiais. Nesta edição do Festival $^{17}$, a bioarte não só perpassa propostas que abordam relações metamórficas entre os dispositivos e os ambientes naturais, mas vale-se da tecnologia para criar um vínculo entre diversos mundos sutis e frágeis, e as possíveis ressignificações diante da presença de organismos vivos. Essa concepção, mais recente na Arte Contemporânea, propicia relações transdisciplinares na produção artística, pois a bioarte pode ser considerada como um conceito transversal para pensar a Arte, a Ciência e a Nanotecnologia, suas implicações políticas e éticas no campo da sustentabilidade. 


\section{Exposição Transdisciplinaridade Arte, Ciência e Neurociência ${ }^{18}$ - obra [POR NÃO SER EXISTINDO]: deslocamentos para a empatia (2013-2019)}

Esta exposição de 2020 integra o projeto institucional do CAPES PrInt, na Universidade Federal de Santa Maria. O conceito transdisciplinar é a Neurociencia, que também trata de como o cérebro humano se comunica e de seus processos de memória, cognição, incluindo "a capacidade para escolher entre alternativas de ação - não ação incluída, e estender nossa faculdade para originar e forjar ações futuras" (FUSTER, 2015, p. 22). Esta mostra reúne artistas com propostas distintas, algumas em vídeo adaptadas para mostra online, em função do contexto pandêmico de Covid-19.

A instalação propicia uma experiência sensível de co-criação da obra, que se reconfigura e se atualiza na interação constante do público com as imagens projetadas no espaço. Para Delannoy (2015, p.144-143), a "experiência acontece em um contexto biológico e atualiza os conteúdos de nossa percepção", ao mesmo tempo em que se dá no entorno e no espaço percebido. Afinal se o "espaço físico é distinto do espaço percebido, como se constitui o espaço vivido, como espaço corporal e espaço de ação", inclusive de projeção. A obra revisita 'Narciso', mas contrasta o mito narcísico da contemplação apaixonada da própria imagem quando potencializa o sentimento de empatia no público, por meio da percepção de sua imagem e de si próprio como condição à alteridade. "[Por Não Ser Existindo]: deslocamentos para a empatia" tanto discute a empatia na convivência com os outros, quanto cumpre o que se propõe na interação ativa do público, ao provocar emoções, ativar memórias e gerar deslocamentos em direção à empatia. No campo transdisciplinar, aproxima Arte, Neurociência e Computação.
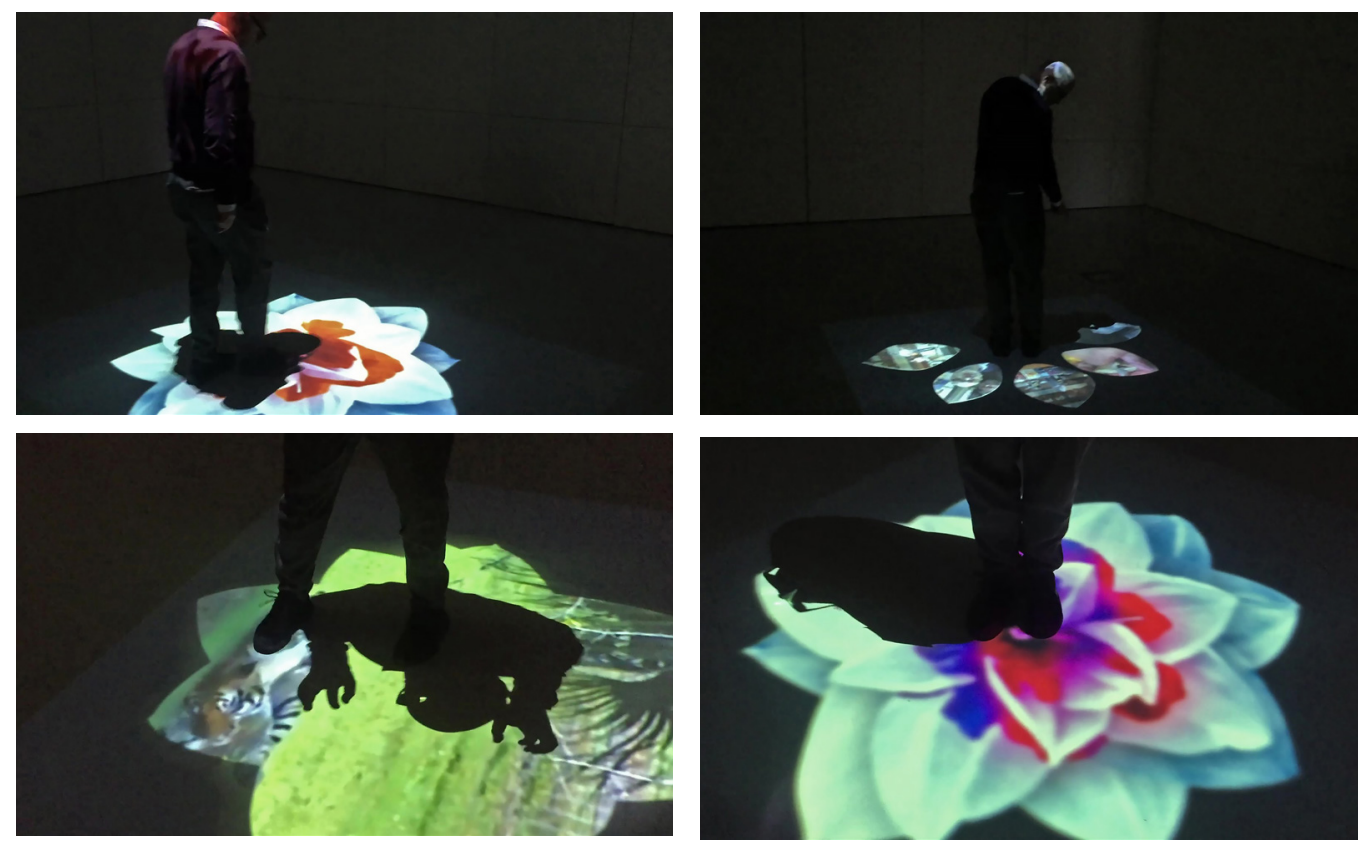

Fig 3. [POR NÃO SER EXISTINDO]: deslocamentos para a empatia (2013-2019), Rachel Zuanon e Geraldo Lima UAM/UNICAMP | Computação cognitiva, ubíqua e instalação interativa Fotografia: Acervo artista para LABART/ UFSM. 
O conceito de Neurociência se abre para um universo de complexidade, onde o corpo humano é capaz de administrar nossa percepção da realidade, construindo uma relação inédita com o espaço e o tempo, para pensar a memória, a cognição e a empatia como experiência sensível na arte. Na Arte Contemporânea, as diferentes linguagens ou tendências geram poéticas artísticas que se apropriam e se constituem através do vivo e natural, tanto quanto do robótico e artificial, para desconstruir experiências perceptivas e sensoriais pré-estabelecidas e transformar os modos de sentir.

\section{Finalizando}

O curador na área da Arte parte de seu lugar de investigação e pode estabelecer um vínculo com pesquisadores de outras áreas, como a Ciência e Tecnologia, cujo trabalho, processo e resultado da investigação apontam questões que não pertencem mais a nenhuma das áreas, mas ao que se constitui para além delas, ou seja, um campo de conhecimento transdisciplinar em constante emergência.

As três exposições apresentam-se como escolhas pertinentes para analisar as estratégias curatoriais, tanto na concepção de transdisciplinaridade como argumento abordado nas exposições Mata 200 milhões de anos (2011), FACTORS 4.0 (2017) e Transdisciplinaridade Arte, Ciência e Neurociência (2020), quanto nos respectivos conceitos específicos de nanoarte para a obra "Tecendo o Tempo ou Sendo Tecida pelo Espaço", bioarte para a obra "Bot_anic", e neurociência para [POR NÃO SER EXISTINDO]: deslocamentos para a empatia (2013-2019).

A concepção de transdisciplinaridade como argumento curatorial em exposições de Arte-Ciência-Tecnologia aponta diferentes conceitos a cada mostra e gera questões emergentes, provocadoras de novas práticas expositivas e outros discursos para pensar o campo da Arte Contemporânea e sua história. Nesse sentido, podemos pensar as exposições como ações transdisciplinares cujos conceitos problematizam não apenas as mostras, mas também aquilo que poderia ou não se configurar como tendência na Arte? As curadorias podem ser entendidas como multidimensionais? E se o forem, estas exposições em Arte Contemporânea se configurariam como Trans-históricas? 
1 GROYS, Boris. Volverse Público. Buenos Aires: Caixa Negra, 2018, p. 83-100. Na cena artística contemporânea, para ele, seria um tipo de time-based art, que também estaria associada a arte do vídeo, da instalação, cinema, dos meios, e de sua documentação, que se exibe hoje diante de um "espectador em movimento", cujo o tempo é seu verdadeiro con-temporâneo.

2 WILSON, Stephen. Information Arts: intersection of Art, Science and Technology. London/Massachussets: MIT Press, 2002.

WILSON, Stephen. Art Science Now. New York: Thames \& Hudson, 2010. 3 A curadoria na arte contemporânea se tornou amplamente reconhecida como uma profissão significativa, presa nos impulsos centrais da vida contemporânea, mas também capaz de oferecer interpretações surpreendentemente originais das complexidades e contradições de nossa contemporaneidade. SMITH, Terry. Talking Contemporary Curating. New York: ICI, 2015, p. 15.

4 https://pt.scribd.com/document/155577806/Carta-de-Transdisciplinaridade

5 Para pensar a questão, a partir de: BOURDIEU, Pierre. Science de la science et reflexivité. Paris: Raisons d'agir, 2001.

6 Compartilhada entre pesquisadores da área de Artes Visuais, seniores do Brasil e exterior, como também com estudantes em formação no grupo de Pesquisa Arte e Tecnologia/CNPq, mestrandos, doutorandos e pós-doutorandos do Programa de Pós-Graduação em Artes Visuais/PPGART/UFSM, Brasil. www.ufsm.br/labart e https://www.ufsm.br/cursos/ pos-graduacao/santa-maria/ppgart/

7 KAPOULA, Zö̈; VOLLE, Emmanuelle; RENOUL, Julient; ANDREATTA, Moreno (Editores). Exploring Transdisciplinarity in Art and Sciences. Cham: Ed. Springer, 2018, p. 5 .

8 FREIRE, Cristina (org). Walter Zanini. Escrituras Críticas. São Paulo: Anna Blume/Mac USP, 2013, p. 79-80. Mais informações em: JESUS, Eduardo (org). Walter Zanini: Vanguardas, Desmaterialização, Tecnologias na Arte. São Paulo: WMF Martins Fontes, 2018.

9 Cabe enfatizar que a concepção de transdisciplinaridade, aos poucos sedimentada na sequência de exposições a partir de 2011, se mostrou muito adequada aos projetos curatoriais desenvolvidos por esta pesquisadora e pelo grupo de pesquisa Arte e Tecnologia/CNPq, junto ao Laboratório de Pesquisa em Arte Contemporânea, Tecnologia e Mídias Digitais/LABART/PPGART/UFSM. Endereço institucional: www.ufsm. br/labart Redes Sociais: www.instagram.com/labart.ufsm/ e www.facebook.com/labart1228. Também pelo YouTube https://www.youtube. com/channel/UCw274rzHP9t7muJG9zAW_aw

100 discurso dos curadores pode ser exercido em três níveis: o projeto curatorial, texto e catálogo, em que pode se apresentar uma posição pessoal; a prática curatorial na organização da exposição, em que pode ser considerado autor; e, a posição do curador no mundo da arte, em que se evidencia a relação que tem sua atividade com artistas, críticos, incluindo mercado e instituições. GLICENSTEIN, Jérôme. L'Invention du Curateur. Paris: Presses Universitaires de France, 2015, p.180.

11 No ano de 2009, a artista Anna Barros esteve em Santa Maria-RS, Brasil, participando do $4^{\circ}$ Simpósio de Arte Contemporânea: curadoria e crítica. Antes de chegar à cidade, demonstrou interesse em conhecer a cidade da Mata na mesma região central do estado, o que Ihe foi oportunizado através de uma expedição à "Cidade de pedra que já foi madeira". No ano seguinte a artista apresenta no $5^{\circ}$ Simpósio de Arte Contemporânea: poéticas digitais, o resultado de suas pesquisas em nanoarte, com a instalação "200 Milhões de Anos: Árvore Pedra", na Exposição Arte-Poética-Digital. Foi esta obra que inspirou a exposição Museu Interativo Arte, Ciência, Tecnologia e Patrimônio Cultural: Mata 200 milhões de anos em (2011), que aconteceu no Museu de Arte de Santa Maria/ MASM, com curadoria colaborativa de Nara Cristina Santos, das Artes Visuais, e Maria Rosa Chitolina, das Ciências, ambas da UFSM. Dados disponíveis em: https://www.ufsm.br/museus/arte-ciencia-tecnologia/ museu-interativo-arte-ciencia-tecnologia-e-patrimonio-cultural-mata-200-milhoes-de-anos/

DATJournal v.6 n.1 2021 
12 A nanoarte, como outras nomenclaturas utilizadas pelos artistas nas produções em Arte, Ciência e Tecnologia, decorre de uma área específica, neste caso da nanotecnología ou nanociência, que trabalha com estruturas de dimensões muito pequenas, entre 1-1000 nanômetros (um nanômetro [nm] compreende um bilionésimo de um metro [m]), seja na engenharia molecular, para colocar cada átomo e cada molécula no lugar desejado, seja na ciência dos materiais para se aproximar de nanopartículas (gerando imagens de interesse estético), por exemplo. No caso de Anna Barros, as imagens em escala nano, que a artista trabalha através da animação, foram obtidas através de Microscópio Eletrônico de Varredura e Microscópio de Força Atômica, a partir dos fragmentos de madeira petrificada.

13 Mata-RS, Brasil, "Cidade de pedra que já foi madeira". Patrimônio Paleobotânico em decorrência de grande número de madeira petrificada, com idade de 200 milhões de anos.

14 Parte de texto da artista para flyer da exposição. Santa Maria, 2011. Publicado posteriormente em versão atualizada em BARROS, Anna. Nanoarte. São Paulo: Ed SESI-SP, 2013, p. 52.

15 O Festival Arte Ciência e Tecnologia expõe anualmente desde 2014, obras e projetos de artistas brasileiros e desde 2016 também de ibero-americanos, todos com pesquisas consolidadas ou emergentes, que colaboram para pensar e questionar a Arte hoje. Os artistas convidados têm suas obras selecionadas através de uma curadoria compartilhada, e na quarta edição, em 2017, por Nara Cristina Santos/UFSM e Mariela Yeregui/UNTREF. A mostra reúne artistas nacionais e estrangeiros: Ana Laura Cantera, Paula Guerzensvaig, Robots Mestizo, da Argentina; Gabriela Munguía e Lupita Chávez, do México; Eduardo Kac, residente nos EUA: Fernando Codevilla e Leonardo Arzeno, Gilbertto Prado e Grupo Poéticas Digitais, Guto Nóbrega e Grupo NANO, Raul Dotto e Waleska Timmen, Rebeca Stumm, Yara Guasque, do Brasil. 0 evento integra a primeira BIENALSUR como marco km1055, na Universidade Federal de Santa Maria, Brasil e, desdobrada, no Museu da Universidade Tres de Febrero/UNTREF, Caseros, Província de Buenos Aires, Argentina. https:// www.bienalsur.org/es

16 RINCÓN, Daniel Lopez. Bioarte. Arte y vida en la era de la biotecnología. Madri: AKAL, 2015.

17 SANTOS, Nara Cristina; YEREGUI, Mariela (org.) FACTORS 4.0 é BIENALSUR. Santa Maria: Ed PPGART, 2018. Catálogo disponível em: https://www.ufsm.br/app/uploads/sites/740/2018/08/Catlogo_FACTORS_OK-1.pdf

18 A exposição "Transdisciplinaridade Arte Ciência e Neurociência", foi organizada para acontecer junto ao evento Transdisciplinaridade nas Ciências e nas Artes, vinculada ao projeto institucional CAPES PrInt/ UFSM. A mostra reúne artistas brasileiras e estrangeiras que trabalham questões em torno da arte em diálogo com a ciência, a neurociência e também com a tecnologia. São elas Raquel Zuanon e Tania Fraga, do Brasil; Mariela Yeregui, da Argentina; Maria Manuela Lopez e Marta de Menezes de Portugal; e, Pia Tikka, da Finlândia. Curadoria de Nara Cristina Santos e pós-doc Hosana Celeste Oliveira PPGART/UFSM. Online no Instagram da Sala Cláudio Carriconde e LABART, em função da pandemia de Covid-19. Catálogo disponível em https://www.ufsm.br/app/ uploads/sites/740/2020/12/catalogo_transdisciplinaridade_.pdf 


\section{Referências}

BARROS, Anna. Nanoarte. São Paulo: Ed SESI-SP, 2013.

BOURDIEU, Pierre. Science de la science et reflexivité. Paris: Raisons d'agir, 2001.

FREIRE, Cristina (org). Walter Zanini. Escrituras Críticas. São Paulo: Anna Blume/Mac USP, 2013.

FUSTER, J. M. Neurociencia. Los cimentos cerebrales de nuestra libertad. Ciudad de México: Ediciones Culturales Paidós, 2015.

GLICENSTEIN, Jérôme. L'Invention du Curateur. Paris: Presses Universitaires de France, 2015. GROYS, Boris. Volverse Público. Buenos Aires: Caixa Negra, 2018.

KAPOULA, Zoï; VOLLE, Emmanuelle; RENOUL, Julient; ANDREATTA, Moreno (Editores). Exploring Transdisciplinarity in Art and Sciences. Cham: Ed. Springer, 2018.

MACT. https://www.ufsm.br/museus/arte-ciencia-tecnologia/museu-interativo-arte-ciencia-tecnologia-e-patrimonio-cultural-mata-200-milhoes-de-anos/

RINCÓN, Daniel Lopez. Bioarte. Arte y vida en la era de la biotecnología. Madri: AKAL, 2015. SANTOS, Nara Cristina; YEREGUI, Mariela (org.) FACTORS 4.0 é BIENALSUR. Santa Maria: Ed PPGART, 2018. Disponível em: https://www.ufsm.br/app/uploads/sites/740/2018/08/Catlogo_FACTORS_OK-1.pdf SANTOS, Nara Cristina; CELESTE, Hosana (org.) Transdisciplinaridade Arte, Ciência e Neurociência. Santa Maria: Ed PPGART, 2020. Disponível em: https://www.ufsm.br/app/uploads/ sites/740/2020/12/catalogo_transdisciplinaridade_pdf SMITH, Terry. Talking Contemporary Curating. New York: ICI, 2015.

WILSON, Stephen. Information Arts: intersection of Art, Science and Technology. London/ Massachussets: MIT Press, 2002. 